\title{
Climate Changes and Vision Loss a Possible Problem of Public Health
}

\section{Sanda Jurja*}

Department of Ophtalmology, Faculty of Medicine, Ovidiusm University Constanţa, Romania

\begin{abstract}
Weather changes raise a major concern during last decades, in all areas, including their consequences on public health. The impact of changing weather on eye pathology was not widely studied. Ocular diseases have a major impact on the quality of life and on working ability. Thus we considered of interest to investigate the possibility of any correlation between meteorological factors and ocular diseases.

Glaucoma is known to be a degenerative multifactorial eye disease, which may lead to blindness. Its pathogeny still remains controversial for ophthalmologists worldwide. This work points out the correlation found between weather factors and acute glaucoma.

Our study included 262 cases of patients, presented in Ophthalmology Department from Constanta Emergency Hospital, between 2002 and 2013. As weather element, the phase's survey offers the opportunity to study glaucoma during stable or changing weather, because it provides the advantage of synthetically vision on the situation of all meteorological factors. Weather changes turned out to have an obvious role in generating acute glaucoma.
\end{abstract}

Keywords: Weather changes; Acute glaucoma; Phase

\section{Introduction}

The last decades, due to permanent technical progress, the study and prediction of the weather have been much improved, allowing a more and more precise evaluation of eventually existing correlations between environment and different aspects of human life and activity. The knowledge of some existing correlations between meteorological factors and health state provides us ways to better prevent some acute and severe conditions, such as acute glaucoma [1-3] and ways to better control chronic diseases evolutions.

The idea of studying the impact of weather changes on acute glaucoma came to our attention under the circumstances of the last decades tendency of increased frequency of the extreme meteorological phenomenon. The role of weather parameters in angle closure glaucoma have already been revealed in some studies [4-6]. We considered worth of interest to see the situation for Constanta region, on the Black Sea coast, by studying the cases of acute glaucoma which occurred during the 2002-2013 period.

\section{Materials and Methods}

Angle closure glaucoma, known also as acute glaucoma, is defined as an extreme high intraocular pressure, which results from a sudden adherence of the iris to the corneoscleral trabeculum, followed by sudden increase of the outflow resistance for the aqueous humor [7] The severe symptoms, of acute onset, force the patients to address to a hospital very soon, providing us the opportunity to know precisely the weather aspects at the onset time. This aspect offers us the means to investigate the eventual existing impact of weather changes on acute glaucoma. Our work included a number of 262 cases of patients, presented in Ophthalmology Department from Constanta Emergency Hospital, between 2002 and 2013. We used the classification proposed by Ungeheur/Tromps in 1970, which includes 6 types of weather, in order to characterize and measure weather in a generally accepted way [8]:

-Phase 1: relatively nice weather, the sky sometimes cloudy, sometimes sunny; temperature and humidity variations within normal limits, pressure increases slightly; the wind is cool and dry, refreshing human organism;
-Phase 2: nice weather, clear sky, pressure slightly decreases; temperature and humidity have important variations from night to day; light wind. This phase is associated with a pleasant heat sensation.

-Phase 3: very nice weather, week foehn, low pressure, temperature increases much over the limit of biological comfort. It's associated with unpleasant feeling, generating mainly migraines.

- Phase 4: represents the start of weather changing, stormy clouds are quickly developing, pressure diminishes while temperature stays relatively high and humidity is increasing, these are the main aspects of the warm front. The weather is perceived as suffocating and uncomfortable.

-Phase 5: weather in full changing; the cold front is penetrating, with decreasing air temperature, cumulus cloudy sky, high humidity and moderate to strong wind. Uncomfortable cold feeling [9].

-Phase 6: weather is improving. Less cloudy, pressure and temperature slowly and constantly increasing, humidity low enough and wind progressively weaker. Perceived as pleasantly cold.

\section{Results}

The possibility to evaluate glaucoma trend during stable or changing weather was provided by the phase's survey, which offers the

*Corresponding author: Sanda Jurja, Faculty of Medicine, Ovidius University Constanta, str.Universitatii C2, Postal Code 900527, Romania, Tel: 0040241615048 E-mail: jurjasanda@yahoo.com

Received December 02, 2014; Accepted February 04, 2015; Published February 06,2015

Citation: Jurja S (2015) Climate Changes and Vision Loss a Possible Problem of Public Health. J Climatol Weather Forecasting 3: 128. doi:10.4172/23322594.1000128

Copyright: (c) 2015 Jurja S. This is an open-access article distributed under the terms of the Creative Commons Attribution License, which permits unrestricted use, distribution, and reproduction in any medium, provided the original author and source are credited. 
Citation: Jurja S (2015) Climate Changes and Vision Loss a Possible Problem of Public Health. J Climatol Weather Forecasting 3: 128. doi:10.4172/2332-2594.1000128

Page 2 of 9

advantage of synthetically vision on the situation of all meteorological factors The annual distribution was relatively balanced: 22 cases in 2003, 20 cases in both 2004 and 2012, 17 cases in both 2005 and 2006, 26 cases in both 2007 and 2008, 23 cases in both 2002 and 2009, 24 cases in 2010, 19 cases in 2011 and 25 cases in 2013 (Figures 1-13).
The evaluation of the correlation between the number of glaucoma crises and the type of meteorological phase during 12 years revealed obvious picks of distribution in phase 5 (most of cases), nearly followed by phase 4 and less phase 3 .

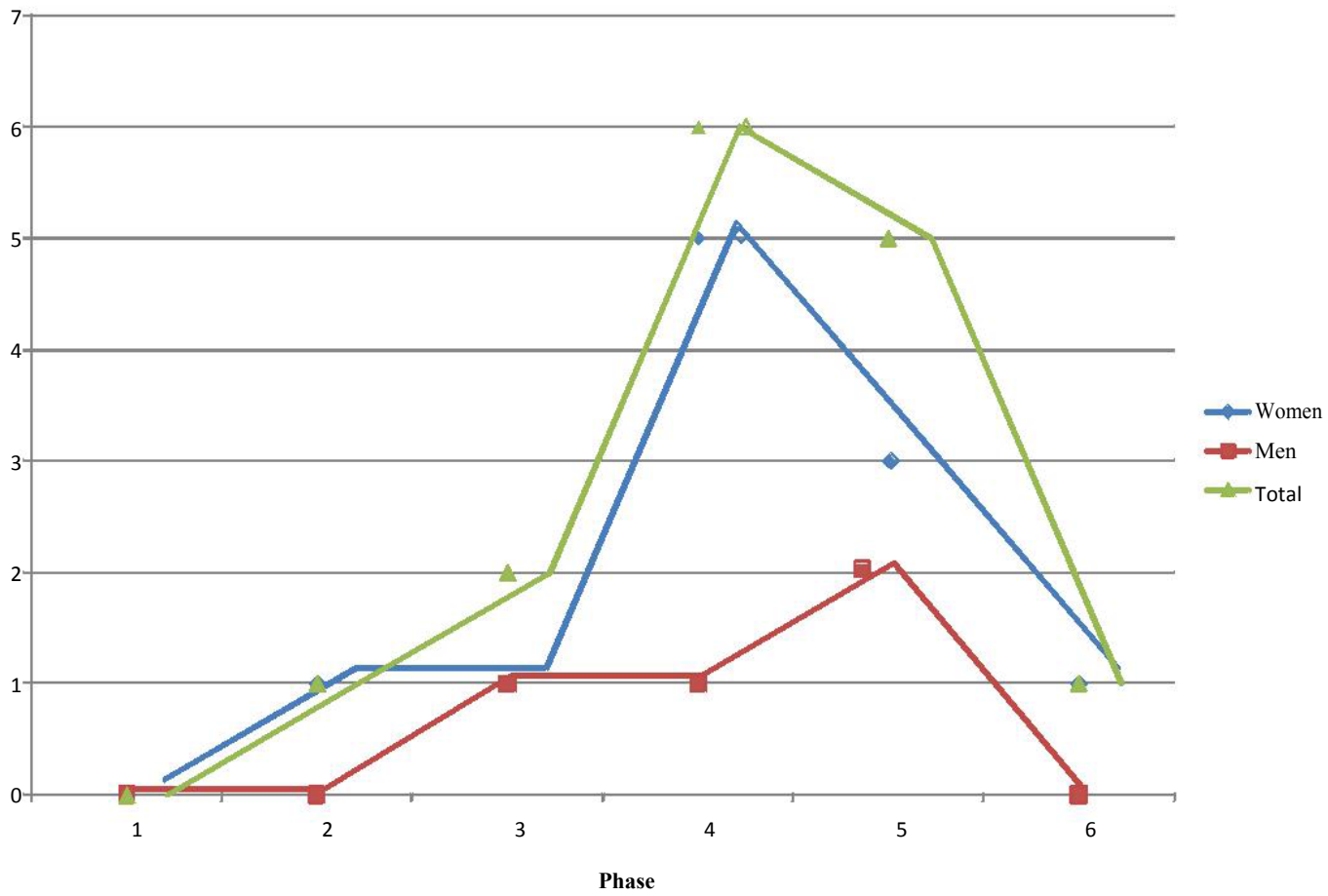

Figure 1: Variation of acute glaucoma cases number depends on phase, in the period 2002.

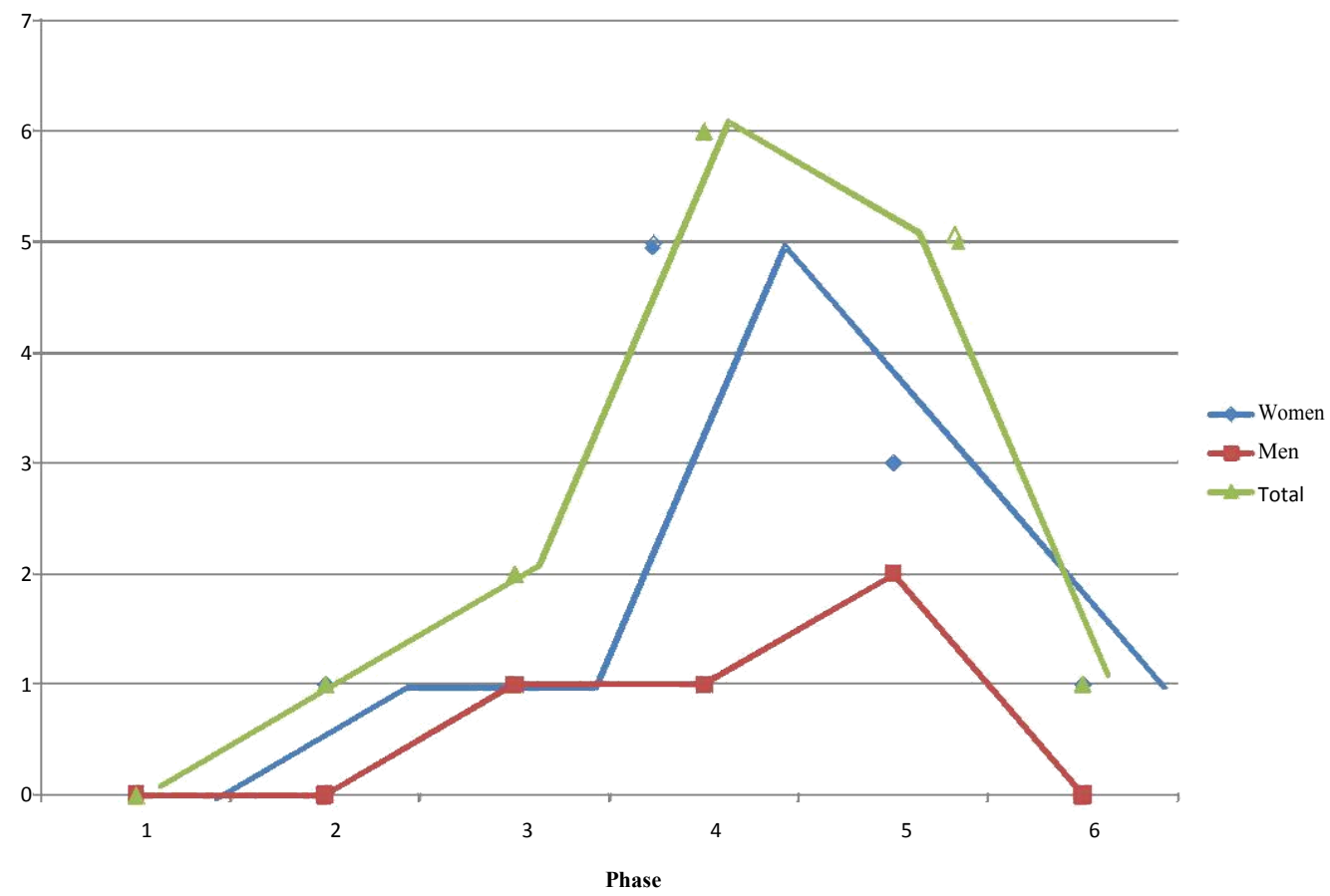

Figure 2: Variation of acute glaucoma cases number depends on phase, in the period 2003 
Citation: Jurja S (2015) Climate Changes and Vision Loss a Possible Problem of Public Health. J Climatol Weather Forecasting 3: 128. doi:10.4172/2332-2594.1000128

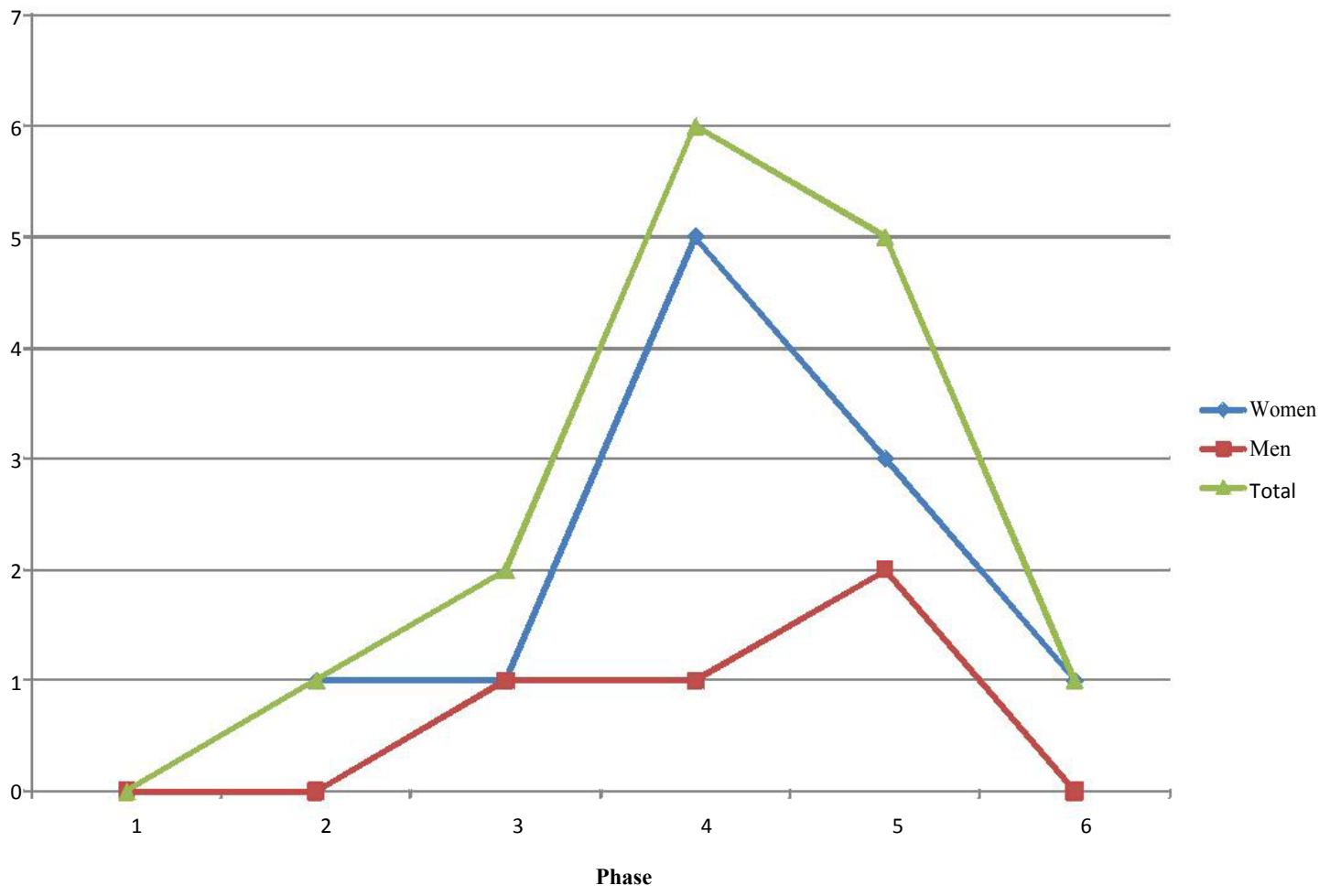

Figure 3: Variation of acute glaucoma cases number depends on phase, in the period 2004.

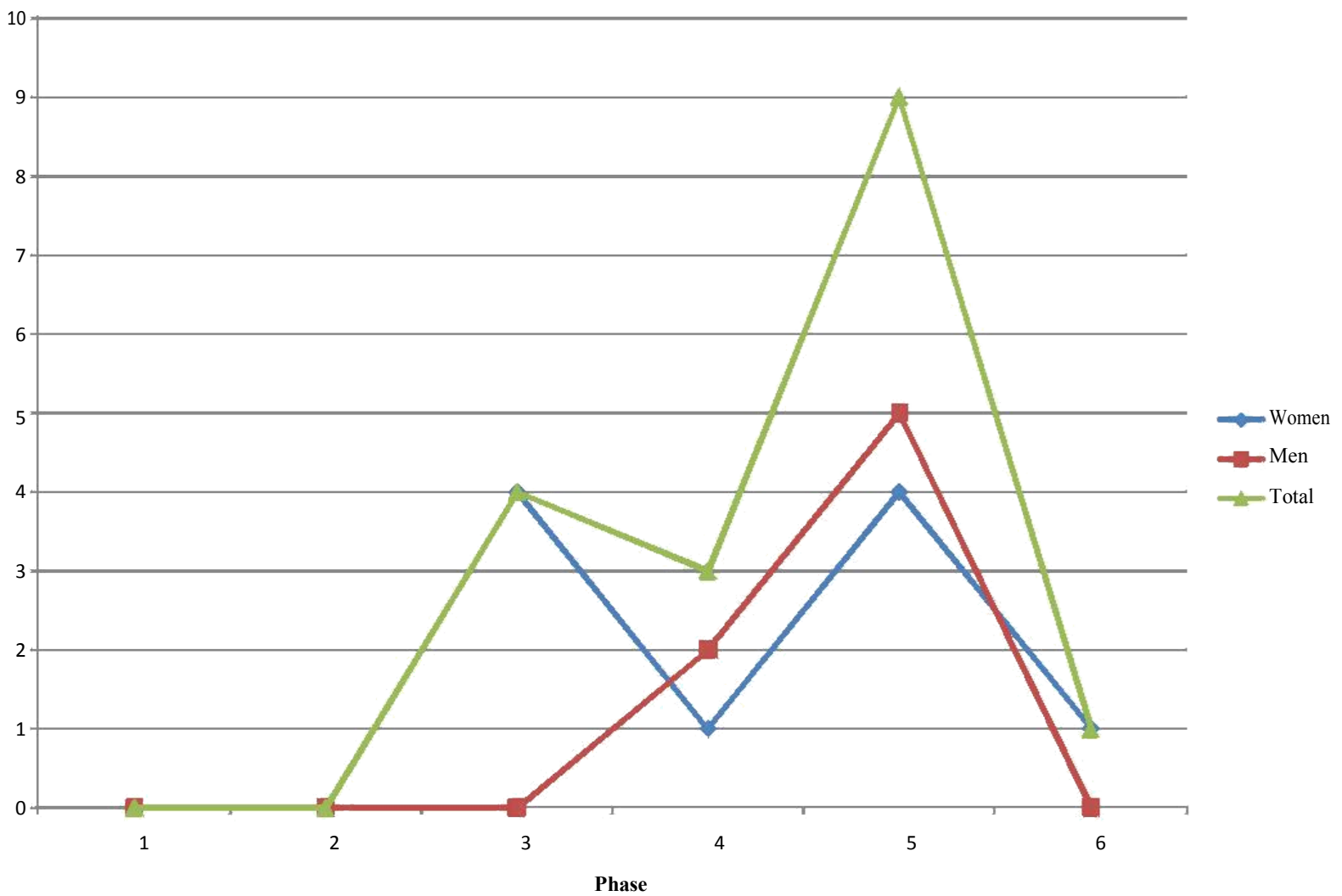

Figure 4: Variation of acute glaucoma cases number depends on phase, in the period 2005. 
Citation: Jurja S (2015) Climate Changes and Vision Loss a Possible Problem of Public Health. J Climatol Weather Forecasting 3: 128. doi:10.4172/2332-2594.1000128

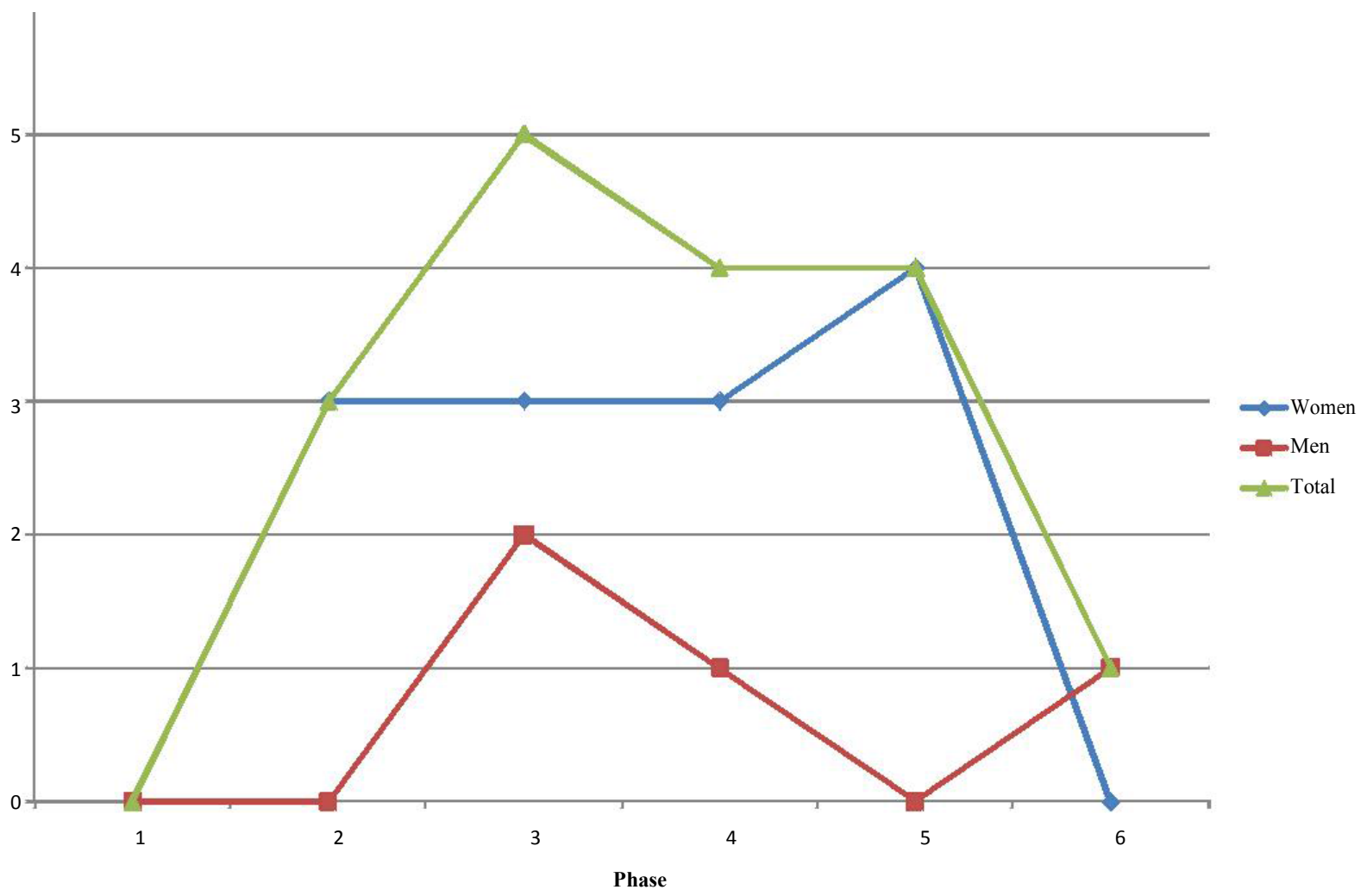

Figure 5: Variation of acute glaucoma cases number depends on phase, in the period 2006.

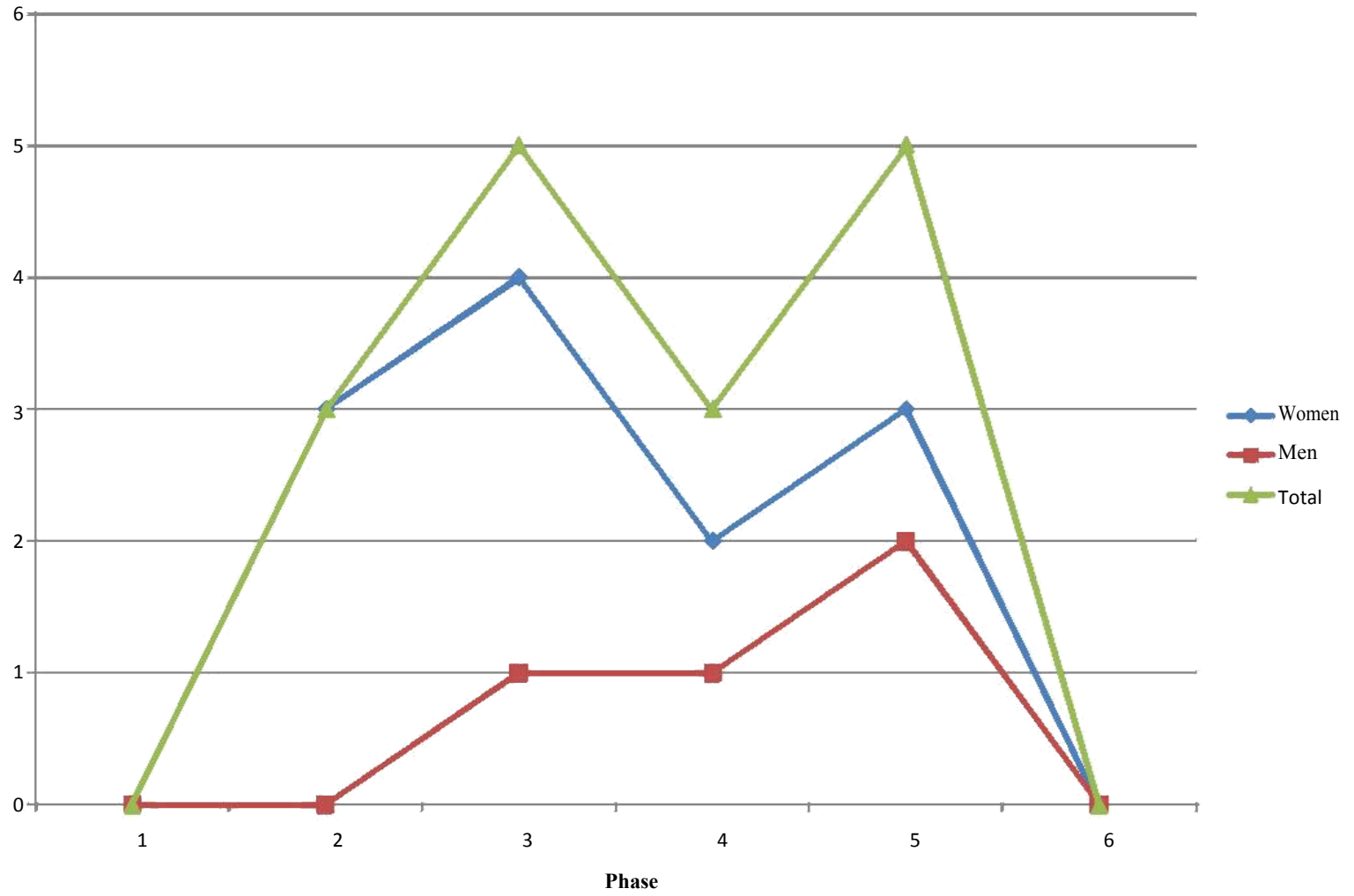

Figure 6: Variation of acute glaucoma cases number depends on phase, in the period 2007. 
Citation: Jurja S (2015) Climate Changes and Vision Loss a Possible Problem of Public Health. J Climatol Weather Forecasting 3: 128. doi:10.4172/2332-2594.1000128

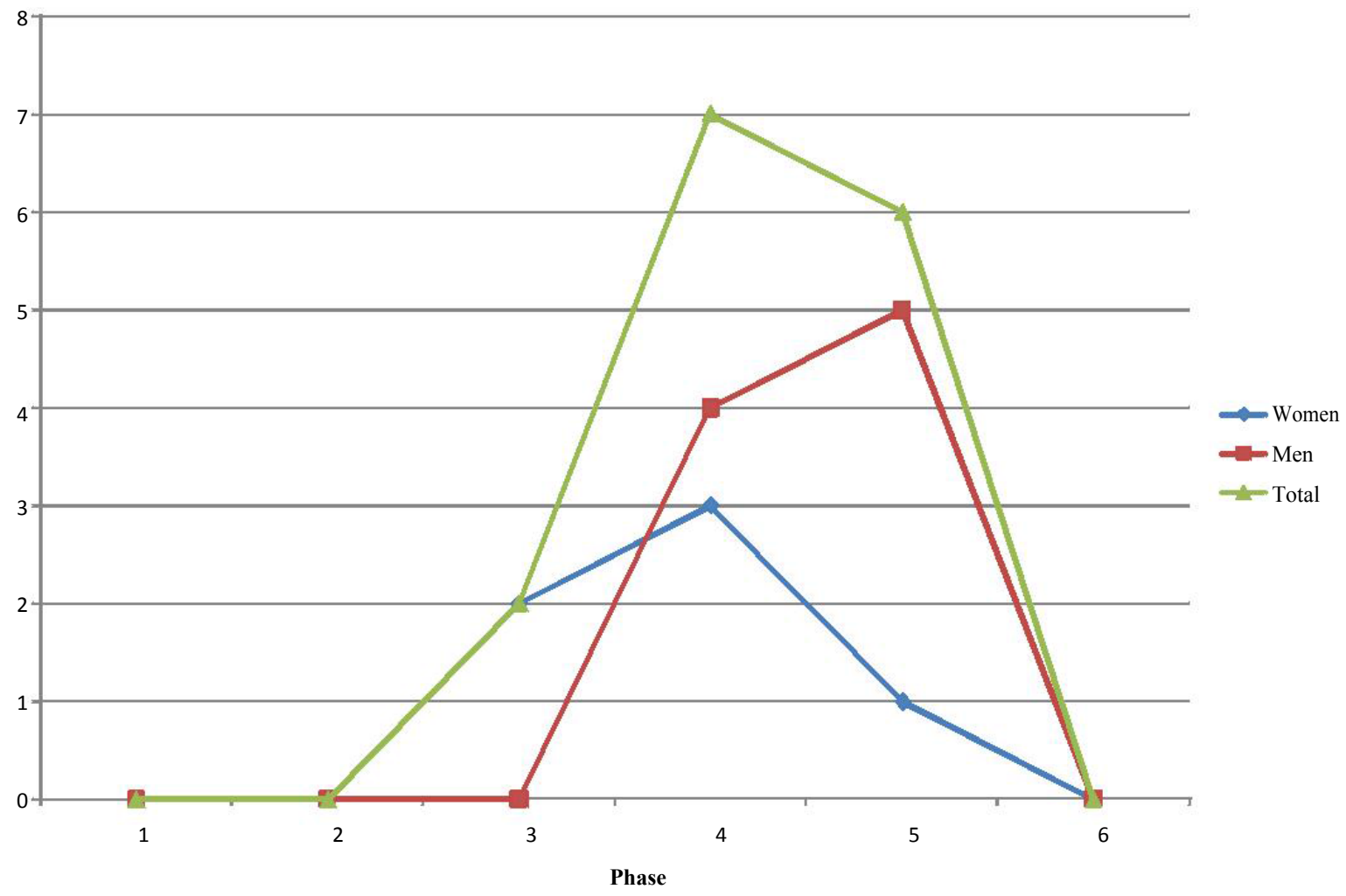

Figure 7: Variation of acute glaucoma cases number depends on phase, in the period 2008.

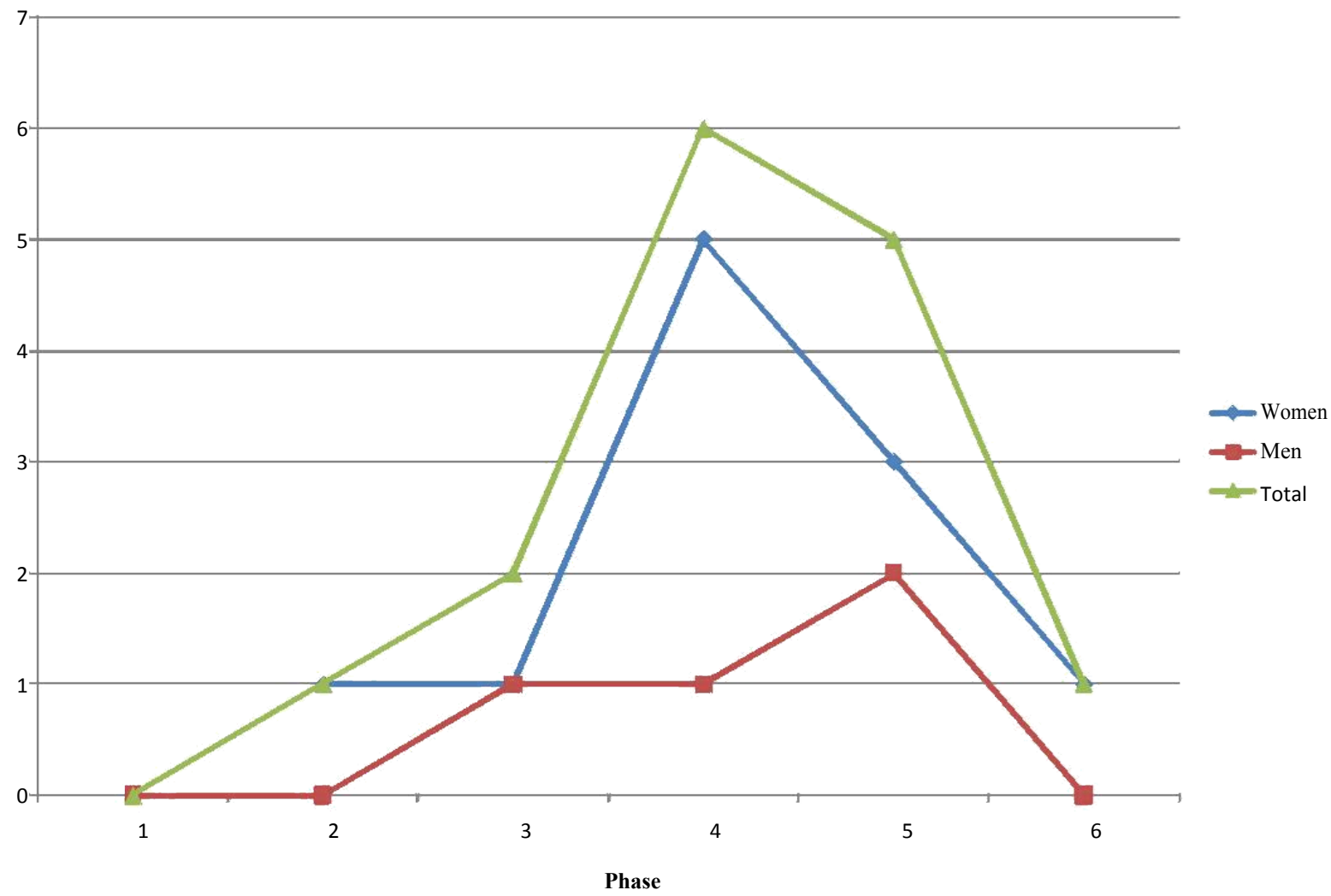

Figure 8: Variation of acute glaucoma cases number depends on phase, in the period 2009. 
Citation: Jurja S (2015) Climate Changes and Vision Loss a Possible Problem of Public Health. J Climatol Weather Forecasting 3: 128. doi:10.4172/2332-2594.1000128

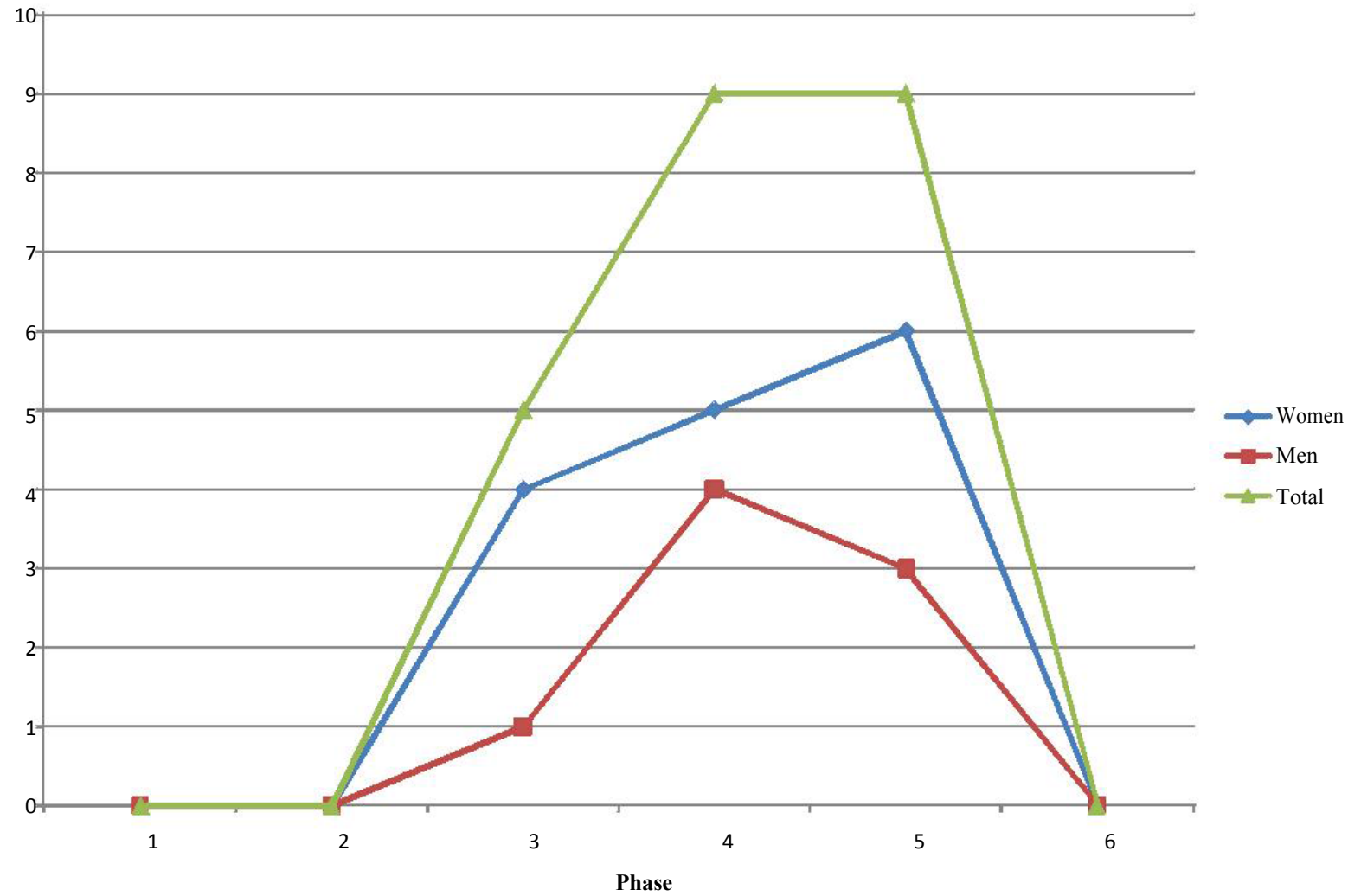

Figure 9: Variation of acute glaucoma cases number depends on phase, in the period 2010.

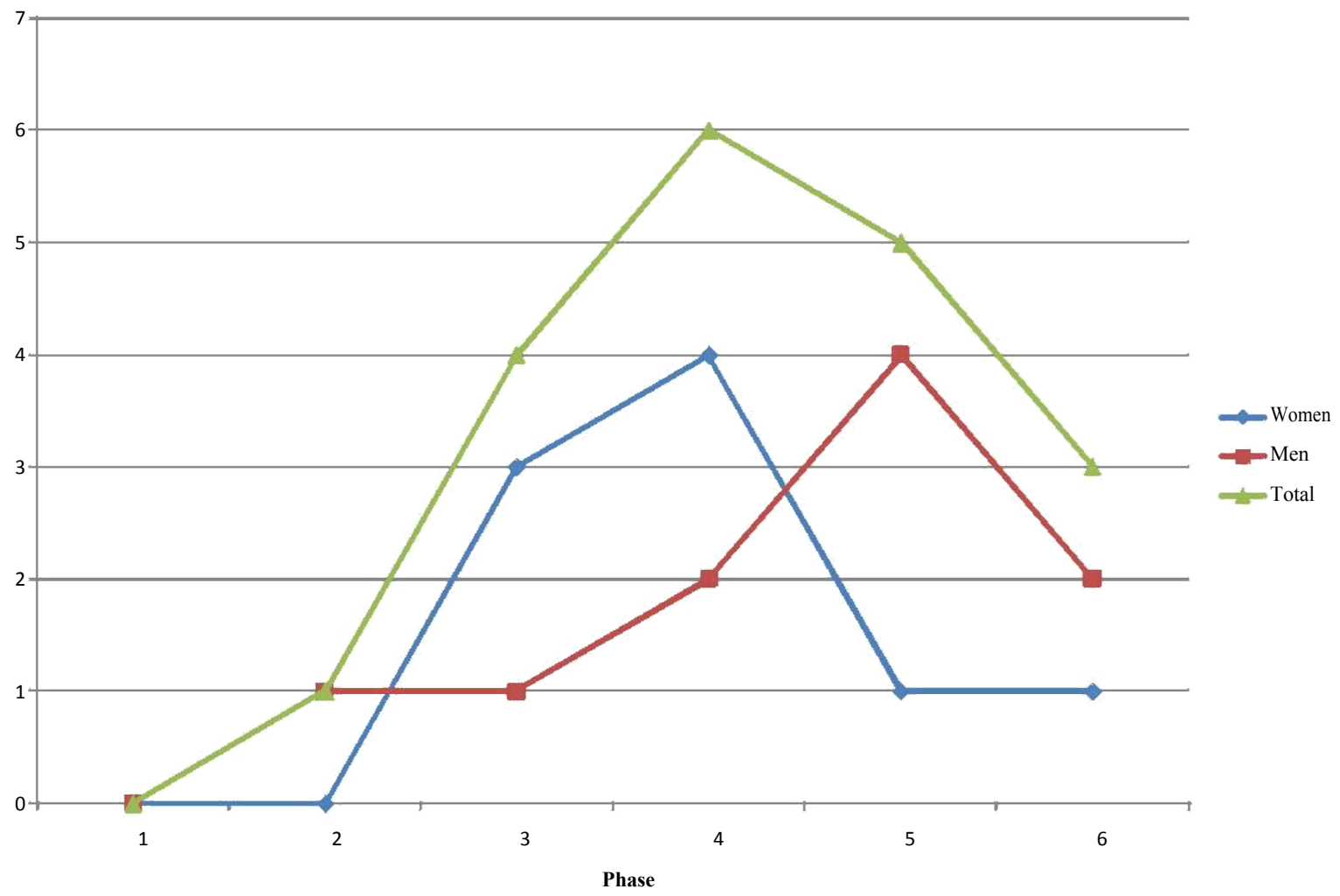

Figure 10: Variation of acute glaucoma cases number depends on phase, in the period 2011. 
Citation: Jurja S (2015) Climate Changes and Vision Loss a Possible Problem of Public Health. J Climatol Weather Forecasting 3: 128. doi:10.4172/2332-2594.1000128

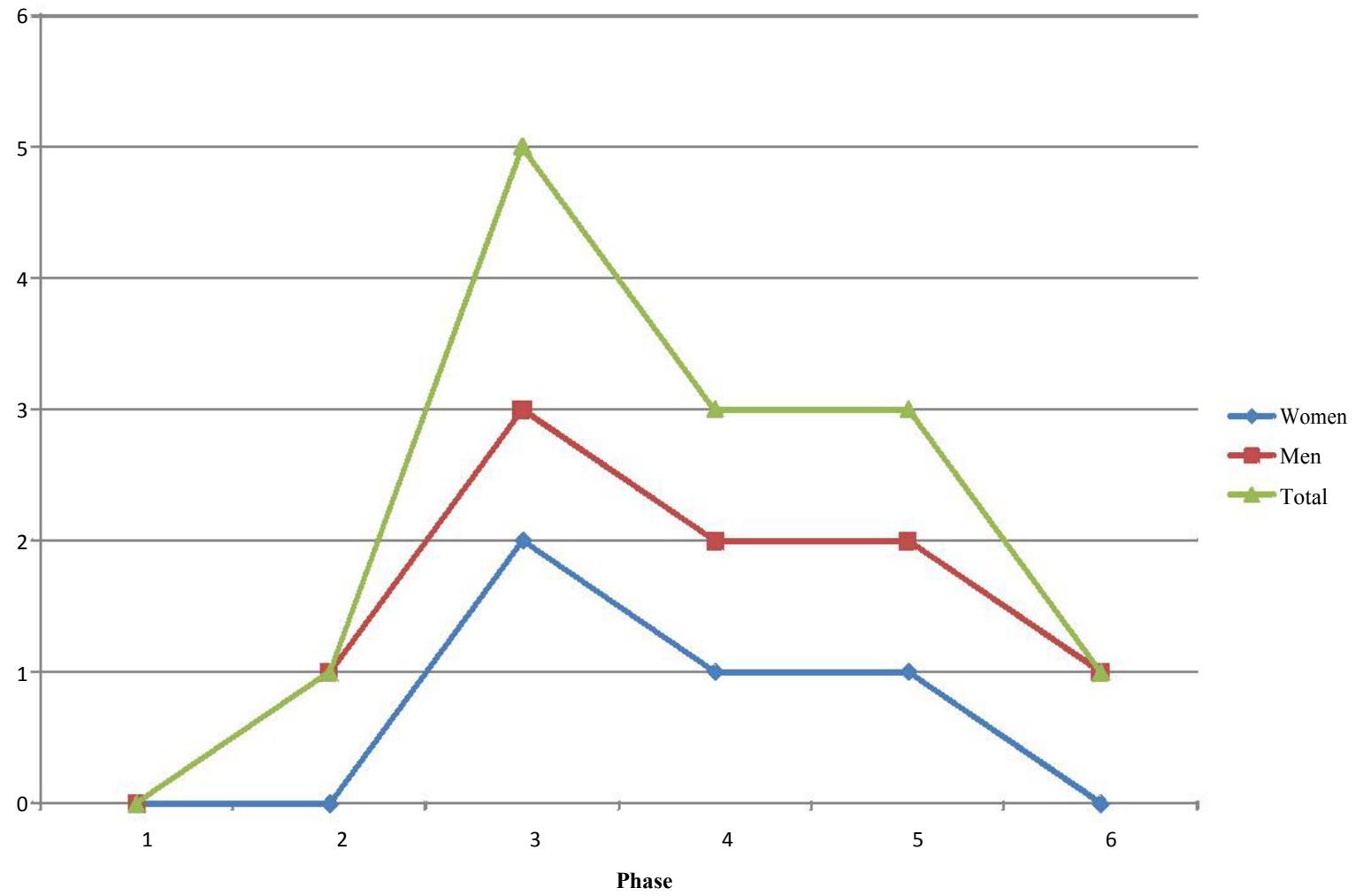

Figure 11: Variation of acute glaucoma cases number depends on phase, in the period 2012.

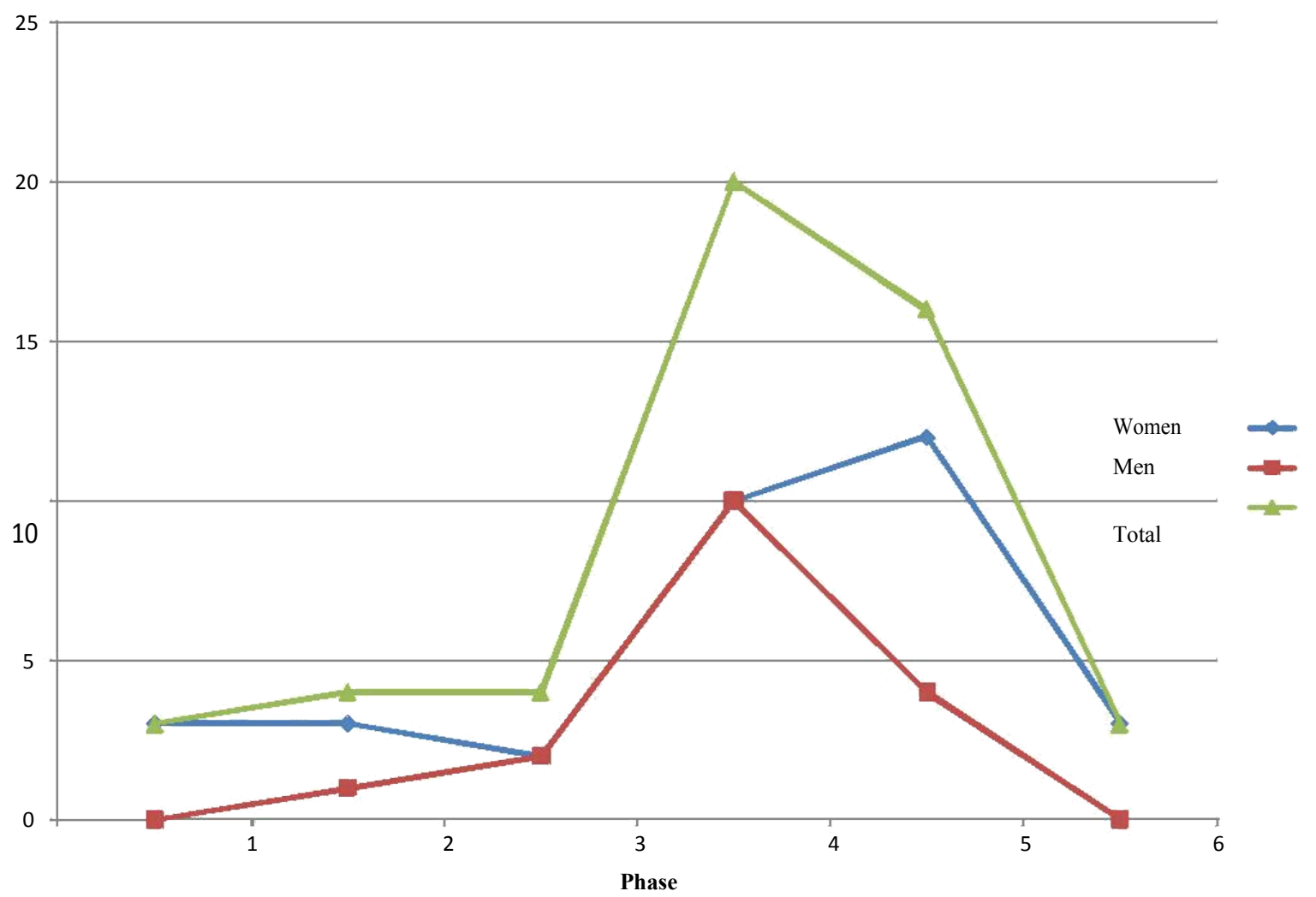

Figure 12: Variation of acute glaucoma cases number depends on phase, in the period 2013. 
Citation: Jurja S (2015) Climate Changes and Vision Loss a Possible Problem of Public Health. J Climatol Weather Forecasting 3: 128. doi:10.4172/2332-2594.1000128

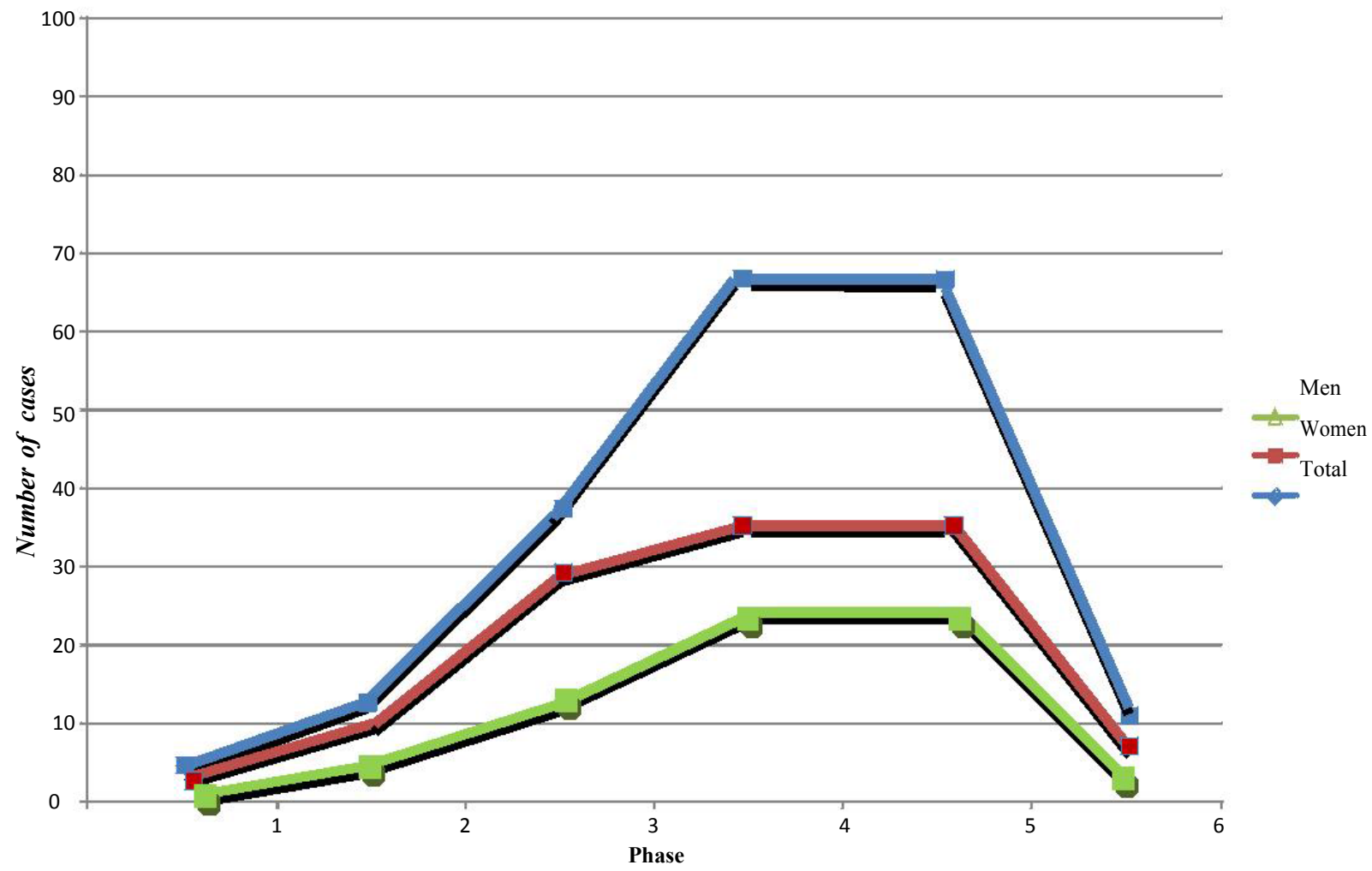

Figure 13: Variation of acute glaucoma cases number depends on phase, in the period 2002-2013.

Acute glaucoma almost didn't occur during phase 1 ( 1 single case in 12 studied years!) and it was very rare in the phases 2 and 6 .

The distribution on genders showed a slight difference. We noticed an almost constant predisposition of men at acute glaucoma during phase 5 , and women were mostly predisposed during phases 4 and 3 .

Our conclusion was that cold front penetration is the most responsible for acute glaucoma, followed by warm front penetration and less by the weather with temperatures over biological comfort limit.

The mechanisms by which the penetration of cold front may cause acute glaucoma onset might be:

- Slowing of transmission on a sympathetic pathway, thus causing the reduction of light re-flexibility and generating midriasis and angle closure.

- Acceleration of general metabolism, including cilliary processes metabolism, cold weather also intensifies aqueous humor production.

During penetration of warm front, the only mechanisms, known until now as being responsible for acute glaucoma onset, are vasodilation and hypophisar antidiuretic hormone hyper secretion. Thus, parasympathetic hypertonia following peripheral vasodilation could cause uveal congestion, known as determinant for angle closure and acute glaucoma.

The weather with temperatures over biological comfort limitphase- 3 would generate acute glaucoma by same processes as warm fronts.

Cold fronts are more risky in generating acute glaucoma in men, and warm fronts and higher temperatures are more risky in women.

The study of the correlation between the distribution of acute glaucoma cases and different meteorological factors leaded us some relevant conclusions:

- The major rate in female gender, possibly caused by higher autonomic nervous system lability;

- Positive tendencies regarding the correlation between acute glaucoma cases and minimal, average, maximal, 1 p.m. temperatures [10-12].

- Non-significant relationship between acute glaucoma cases and temperature amplitude;

- Positive correlation of acute glaucoma with atmospheric pressure;

- Negative correlation of acute glaucoma with sunshine duration $[13,14]$.

- Negative tendencies of correlation between acute glaucoma and Thom and Miss Coefficients.

\section{Discussion}

Environmental impact on human pathology is well-known and accepted, as shown also by other previous studies. A better understanding of its influences on health, including also eyes health, would make this impact more predictable and avoidable. This better understanding might open a way to keep environment friendly to human species, despite our responsibility in weather changes. 
Citation: Jurja S (2015) Climate Changes and Vision Loss a Possible Problem of Public Health. J Climatol Weather Forecasting 3: 128. doi:10.4172/2332-2594.1000128

Page 9 of 9

In conditions of stable weather periods, acute glaucoma occurs either isolated, either doesn't appear at all. Consequently, weather changes have a major role in causing acute glaucoma.

Nowadays, when climate is changing, studying and predicting weather might provide us ways to better prevent acute glaucoma.

The revelation of dangerous weather elements, associated with improvement of weather predictions, would provide a resource of real meteoro-prophylaxis in glaucoma, transforming a potentially blinding disease into an avoidable condition.

\section{Disclosure}

The authors declared no competing interest.

\section{References}

1. 1989 Our planet. Our health, Oms.

2. Santé Humaine et de l'écosistème 1992. Oms.

3. Tromp SW (1963) Medical Biometeorology. Elsevier, Amsterdam-Londra.

4. Fujita K, Negishi S, Fujiki K, Kohyama K, Konsomboon S (1983) Epidemiology of acute angle-closure glaucoma Report I. Jpn J Clin Ophthalmol 37: 625-629.
5. Teikari J, Raivio I, Nurminen M (1987) Incidence of acute glaucoma in Finland from 1973 to 1982. Graefes Arch Clin Exp Ophthalmol 225: 357-360.

6. Clark CV, Mapstone R (1986) Diurnal variation in onset of acute closed angle glaucoma. Br Med J (Clin Res Ed) 292: 1106.

7. Ganem S, Lachkar Y, Vo Tan P (1992) Ophtalmologie clinique. Arnette, Paris.

8. Malone TF (1994) Physical aspects of human bioclimatology. In: Compendium of meteorology, Raven Press, New York.

9. Burton A, Edholm O (1955) Man in a cold environment, psychological and pathological effects of exposure to low temperatures. Edward Arnold, Ltd, London.

10. Cadena C (2009) Seasonal Glaucoma Changes in winter. Seasonal Health \& Wellness 15: 9-15

11. Alsbirk PH (1973) Angle-closure glaucoma surveys in Greenland Eskimos. A preliminary report. Can J Ophthalmol 8: 260-264.

12. Drance S (1973) Angle-closure glaucoma among Canadian Eskimos. Can J Ophthalmol 8: 255- 259.

13. Hillman JS, Turner JD (1977) Association between acute glaucoma and the weather and sunspot activity. Br J Ophthalmol 61: 512-516.

14. Teikari JM, O'Donnell J, Nurminen M, Raivio I (1991) Acute closed angle glaucoma and sunshine. J Epidemiol Community Health 45: 291-293. 